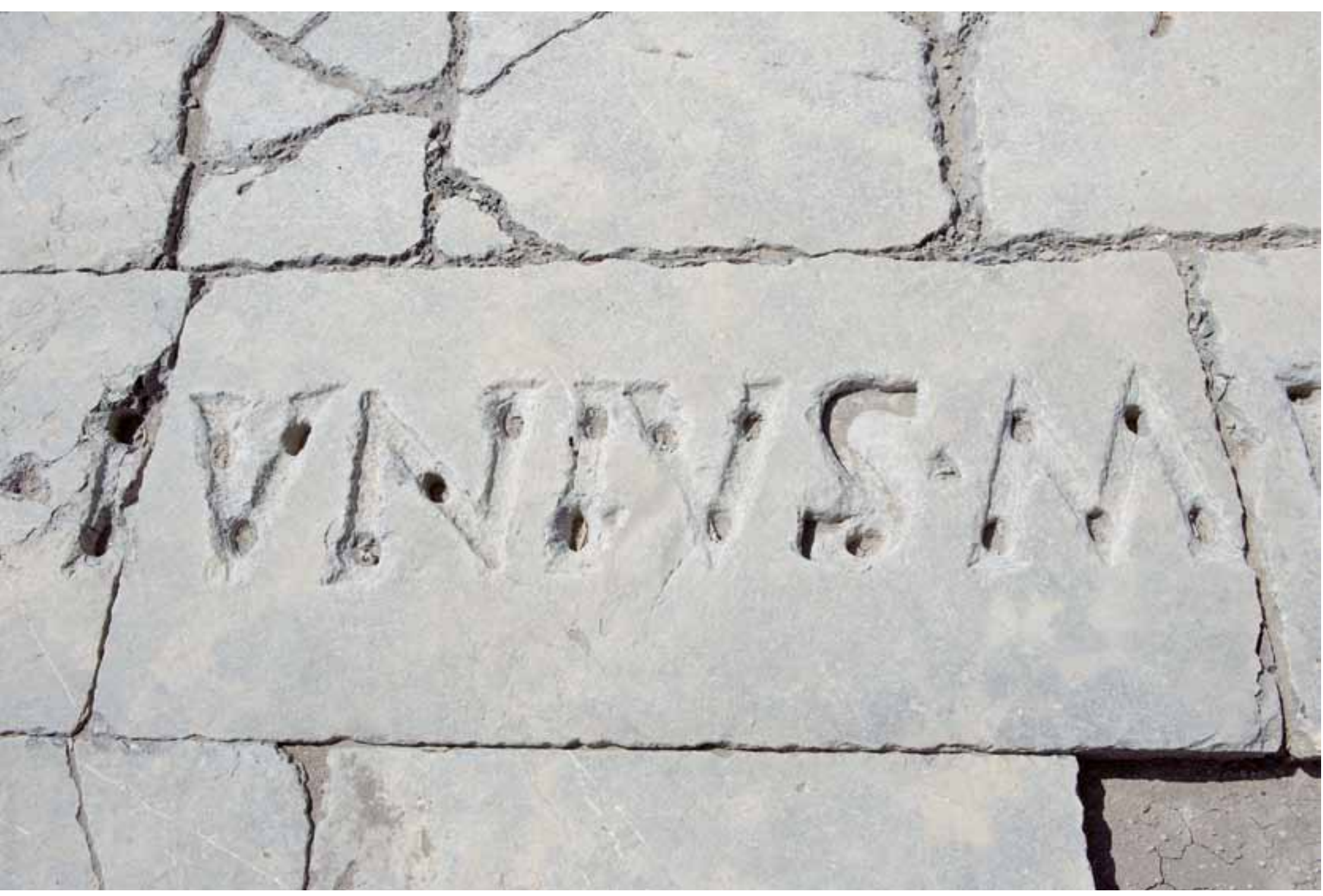

Detalle de la inscripción pavimental del foro romano del yacimiento de Torreparedones con el nombre del mecenas que costeó las obras. Foto: Juan Carlos Cazalla, IAPH 


\title{
Torreparedones: un yacimiento único
}

\author{
José Antonio Morena López, \\ arqueólogo, director del Museo \\ Histórico Municipal de Baena
}

La campiña de Córdoba constituye un territorio de gran riqueza arqueológica que tiene su razón de ser en la extraordinaria fertilidad del terreno y la facilidad para las comunicaciones, como consecuencia de una orografía suave. Estos factores han propiciado la presencia de grupos humanos desde lo tiempos más remotos hasta nuestros dias, habiendo pasado por estas tierras diversas culturas y pueblos: fenicios, cartagineses, griegos, iberos, romanos, visigodos, árabes... Asi se ha podido comprobar en numerosos lugares, algunos de los cuales quedaron abandonados convirtiéndose en yacimientos arqueológicos, mientras que otros continuaron habitados hasta la actualidad.

Entre los primeros podemos citar poblados y ciudades tan interesantes como Ategua (cerca de Santa Cruz), Cerro de Santa María (Lucena), Los Castellares (Puente Genil), Plaza de Armas (Nueva Carteya) y Torreparedones (Baena-Castro del Río), entre otros. En el segundo grupo, hay que citar localidades como Espejo, Montemayor, Aguilar, Castro del Río, Monturque o La Rambla. Muchos de estos lugares se convirtieron en su época en verdaderas urbes fortificadas (oppida) que ocuparon los puntos más estratégicos del territorio y que con la llegada de Roma alcanzaron el rango de municipios o colonias: Ategua, Ucubi Claritas Iulia (Espejo), Ulia (Montemayor), Sabetum (La Rambla), Ipsca (Cortijo de Izcar, Baena), Cerro del Minguillar (Iponoba, Baena), Ipagrum (Aguilar de la Frontera) o Ituci Virtus Iulia (Torreparedones, Baena-Castro del Río).

Estas ciudades estaban bien enlazadas a través de una red de vías y caminos terrestres a la que hay que sumar otro tipo de vías, en este caso fluviales, por las que no sólo se exportaban productos sino que también servian para importar productos exóticos, ya desde la época de las colonizaciones orientales. Además del propio río Guadalquivir (antiguo Betis), hay que mencionar otros cursos fluviales menores, afluentes del gran río, como el Genil (Singilis) o el Guadajoz (Salsum), el primero navegable hasta Astigi (Écija) y el segundo que pudo serlo en algunos tramos.

Todo el territorio campiñés fue ocupado y sometido, en época romana, a una intensa explotación agrícola como evidencian las numerosas villae, antecesoras de los actuales cortijos. El hallazgo de auténticos campos de silos en los que se almacenaba el grano pone de relieve la importancia de los cereales (trigo y cebada), lo que también se confirma a través de las fuentes, pues el escritor Estrabón afirmaba que desde la Bética se exportaba mucho trigo. La espiga y el arado figuran en acuñaciones monetarias de diferentes poblaciones campiñesas como son los casos de Ulia y Obulco (Porcuna), señal inequívoca de su riqueza cerealística. Como complemento a los cereales y formando parte de la llamada triada mediterránea, también se cultivó la vid y el olivo.

Uno de los enclaves arqueológicos más relevantes de la campiña cordobesa lo encontramos en Torreparedones, situado entre los términos municipales de Baena y Castro del Río, en el sector más oriental de la campiña, próximo a la vecina provincia de Jaén y sobre una de las cotas más elevadas de la zona. De la importancia de este lugar para el patrimonio histórico andaluz dan prueba su declaración como Bien de Interés Cultural, con la categoría de Monumento para el castillo medieval, y de Zona Arqueológica para el asentamiento y para la Fuente de la Romana. Por otro lado, hay que destacar la inclusión de Torreparedones, como enclave, en la recién creada Red de Espacios Culturales de Andalucía. Así, no sólo se garantiza su protección y conservación sino que además se promueve su investigación y difusión.

La historiografía sobre Torreparedones, lugar también conocido como Torre de las Virgenes y Castro el Viejo, es muy escasa aunque era bien conocido desde la Edad Moderna por la aparición casual de numerosos vestigios. Ya a mediados del s. XVII el poeta local Miguel de Colodrero y Villalobos visitó el lugar y escribió unos versos en los que se burlaba de la avaricia y superstición de los buscadores de tesoros.

Diversos eruditos se hicieron eco del lugar, pero siempre de una forma tangencial, tratándose de citas puramente nominales para nombrarlo como importante en tiempos de romanos o en relación con el controvertido asunto del martirio de las santas mozárabes Nunilo y Alodia. En el s. XVIII se produjo una errónea iden- 


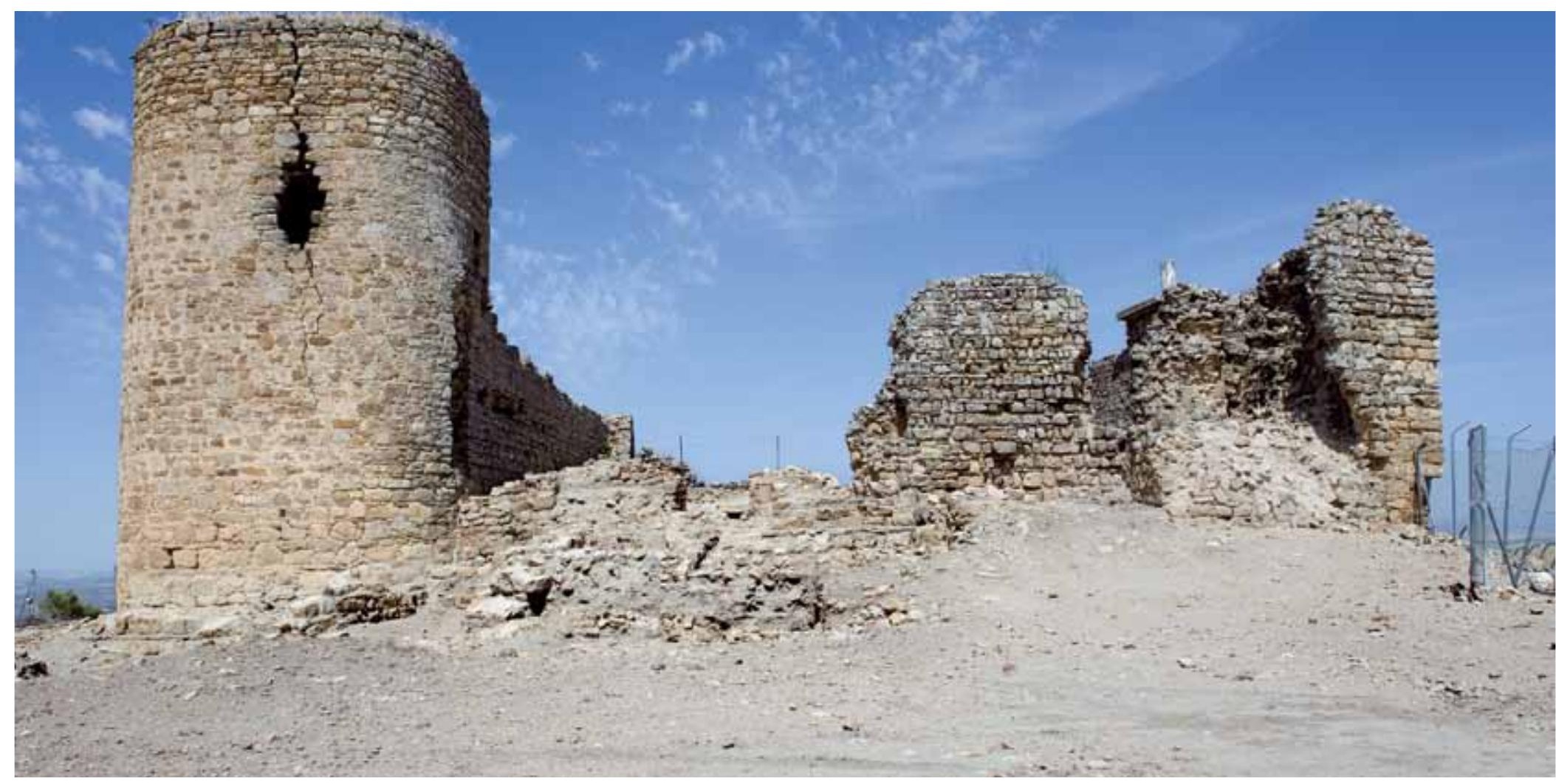

Panorámica del castillo de Castro el Viejo, desde el este. Foto: Juan Carlos Cazalla, IAPH

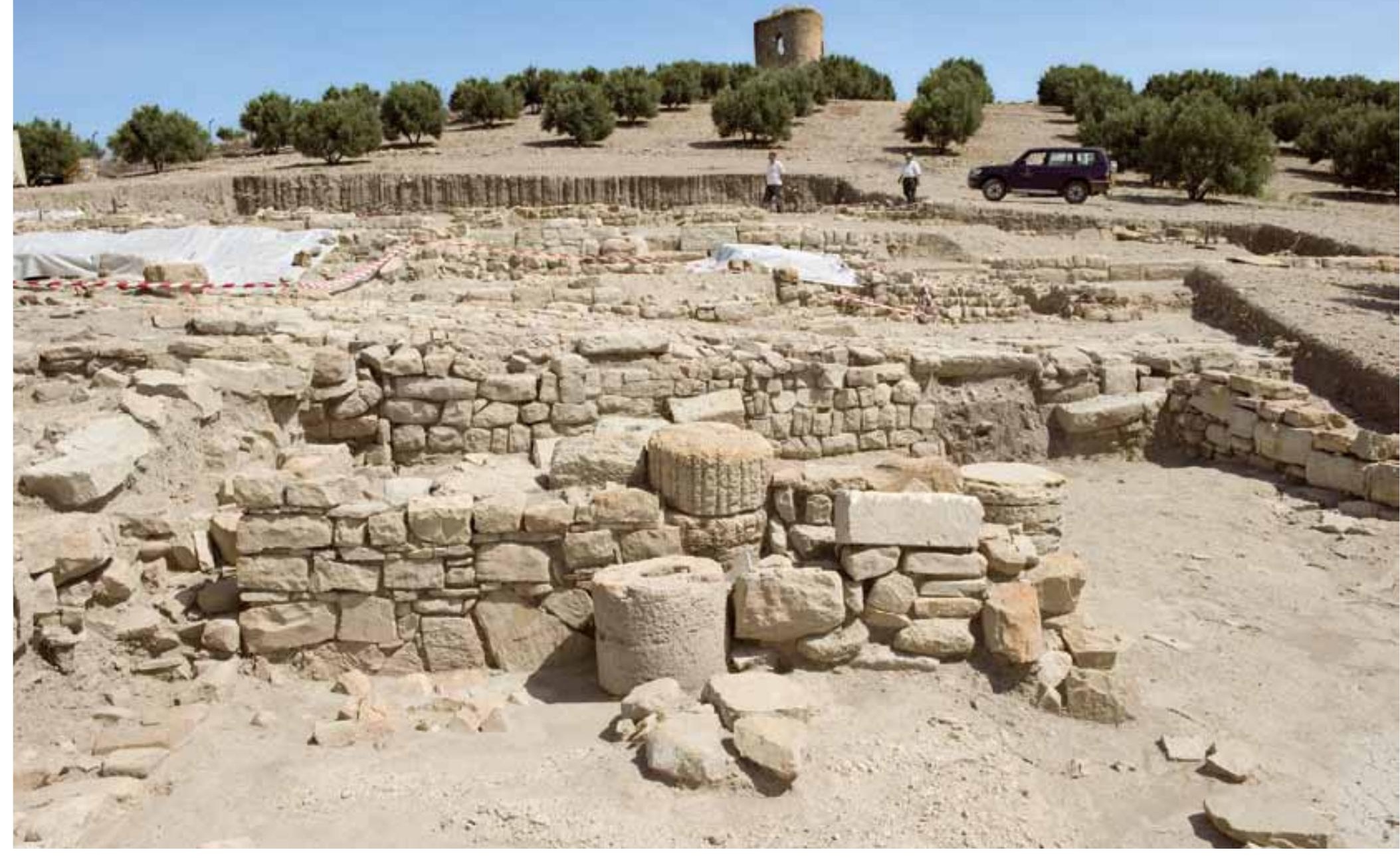



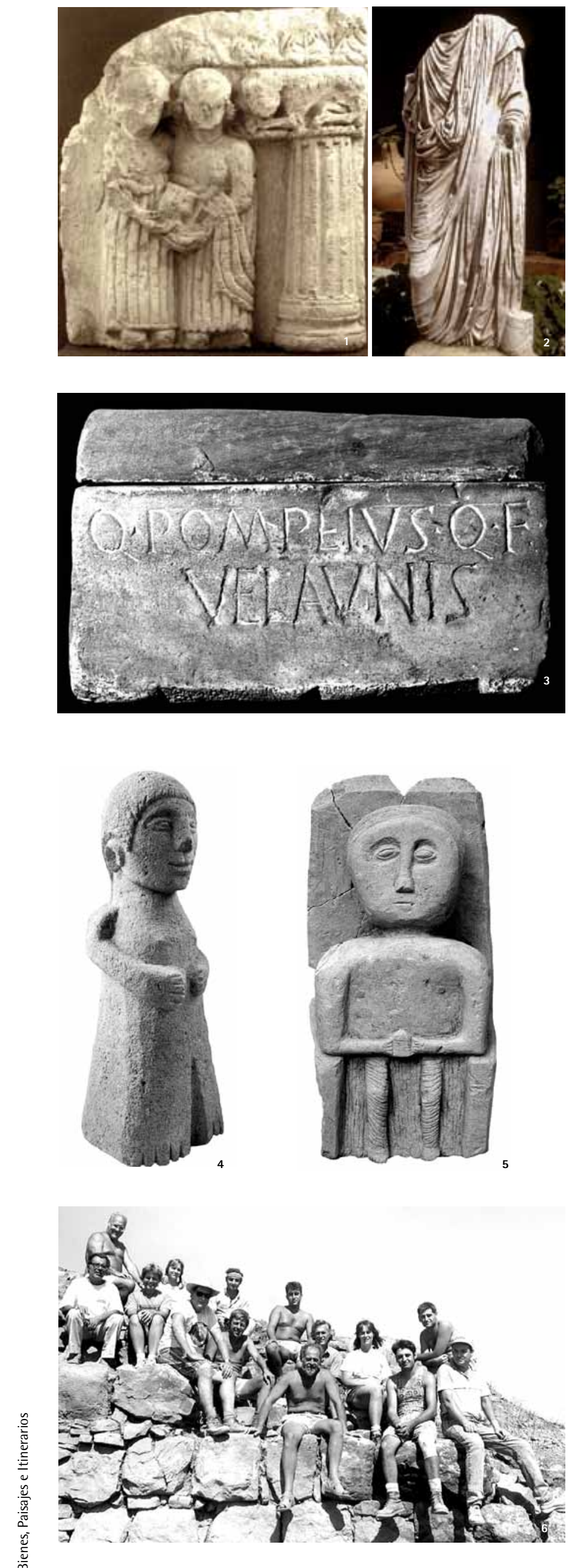

Pero el empuje decisivo que ha puesto a este yacimiento en lo más alto de la actualidad arqueológica lo viene desarrollando desde hace unos años el Excmo. Ayuntamiento de Baena que pretende crear un parque arqueológico, ampliando así la oferta turistica de este municipio cordobés que hasta la fecha se basaba, casi de forma exclusiva, en su reconocida Semana Santa y su afamado aceite de oliva. En apenas cinco años se puede decir que el proyecto marcha a buen ritmo ya que todo el yacimiento es propiedad del consistorio baenense, está vallado y se han realizado varias campañas que han reiterado la importancia del sitio, destacando como elementos más singulares y atractivos la muralla ibérica que rodea el asentamiento, la puerta principal de acceso a la ciudad de época romana, el santuario iberorromano, el centro monumental de la ciudad romana (termas, macellum y plaza del foro), así como el castillo medieval.

Los estudios realizados hasta el momento apuntan a que el lugar estuvo habitado desde el II milenio a. C. hasta el s. XVI, es decir, durante unos 3.500 años, habiendo alcanzado sus momentos de mayor esplendor en las épocas ibérica y romana. Los primeros testimonios materiales de la presencia humana en Torreparedones se remontan a la Edad del Cobre, como se atestigua a través de la prospección superficial y de los resultados de un sondeo realizado en 1990, junto a la puerta oriental. Esta ocupación calcolítica prosiguió durante la Edad del Bronce, en especial durante el Bronce Final (1000-800 a. C.).

A partir del s. VIII a. C. se produjo un fenómeno que cambiaría de manera radical los modos de vida de las comunidades indígenas: la llegada de colonos orientales, fenicios primero, y griegos algo después, en busca de las riquezas metalúrgicas del sur peninsular y también de productos alimentarios. La aculturación que se produjo alcanzó no sólo a la economía y a la cultura material, sino que afectó a la sociedad y conllevó una profunda transformación ideológica.

Ya en época ibérica antigua, en torno al 600 a. C., se construyó una potente muralla con un perímetro de $1 \mathrm{~km}$ delimitando un espacio que supera las 10 ha. Dicha muralla, que puede considerarse como uno de los mejores exponentes de la arquitectura defensiva ibérica de toda la provincia de Córdoba, tuvo un significado social y político determinado evidenciando la presencia de estructuras políticas de carácter estatal, al frente de las cuales estarian personajes integrantes de las élites aristocráticas locales. Torreparedones fue probablemente uno de los oppida principales que conservó y acrecentó su poder en esta época.

Al final de la época ibérica y durante buena parte de la época romana hay que adscribir el santuario extramuros, en el sector meridional de la ciudad. Se han documentado dos edificios des-

1. Relieve iberorromano con escena oferente. Museo Histórico Municipal de Cañete de las Torres (Córdoba). Fuente: Archivo Museo Histórico de Baena 2. Togado. Museo Arqueológico de Córdoba.

Fuente: Archivo Museo Histórico de Baena

3. Urna funeraria de Quinto Pompeio Velaunio. MAN Fuente: Imagines-CIL II2/5, 413

4 y 5. Exvotos. Fuente: Archivo Museo Histórico de Baena

6. Grupo de arqueólogos en la campaña de 1990, dirigidos por Barry W. Cunliffe. Fuente: Archivo Museo Histórico de Baena 


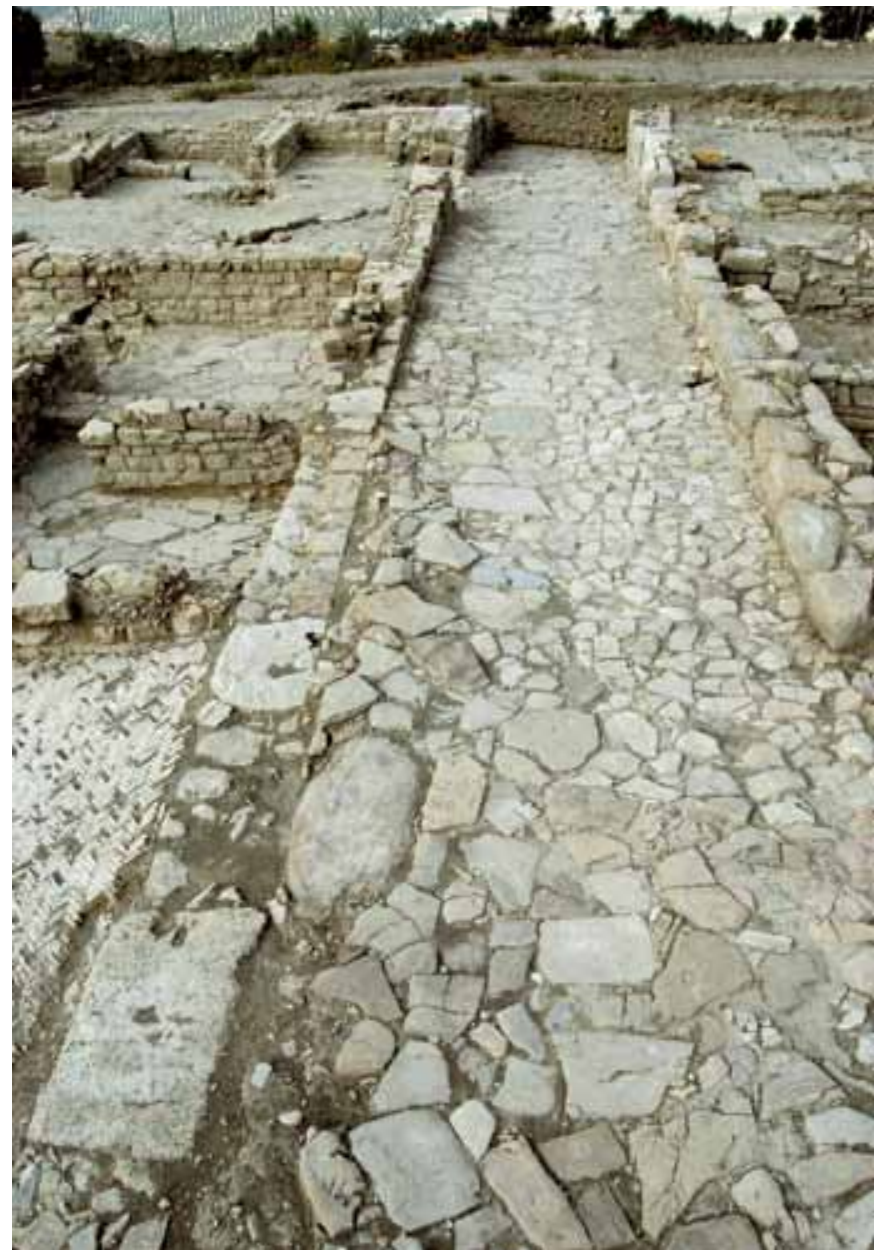

Decumano máximo

Fuente: Archivo Museo Histórico de Baena

Pacificada la zona, la ciudad adquirió un estatuto jurídico privilegiado como evidencian algunas inscripciones que mencionan cargos de la administración municipal (aediles, duoviri...). Es muy probable que el responsable de esta promoción fuese Augusto y que la ciudad no sea otra que la colonia inmune Ituci Virtus Iulia que Plinio menciona en el Conventus Astigitanus. Durante todo el s. I d. C. se llevó a cabo un notable desarrollo urbanístico del que empezamos a conocer algunos elementos como el foro en el que se advierten dos fases constructivas, correspondiendo la segunda a una reforma, datada en época de Tiberio, que conllevó la "marmorización" de la plaza forense y de parte de los edificios ubicados alrededor (el templo, los pórticos y la basílica). Lo más significativo es la pavimentación de la plaza y su inscripción monumental con literae aureae que recuerda el nombre del evergeta responsable de la obra: Marco Junio Marcelo. Cabe destacar la gran similitud que presenta este enlosado con el del foro colonial de Córdoba. La plaza presenta una planta cuadrangular con unas dimensiones de $24 \mathrm{~m}$ en sentido E-0 y $22 \mathrm{~m}$ en sentido $\mathrm{N}-\mathrm{S}$, y una superficie total de $518 \mathrm{~m}^{2}$ (MORENA LÓPEZ; MORENO ROSA, en prensa).

También se han excavado el macellum o mercado de la ciudad y unas pequeñas termas. Los restos escultóricos hallados en el sector del foro (un retrato de Claudio, un togado, una estatua femenina, ambas acéfalas y un fragmento de pierna perteneciente a

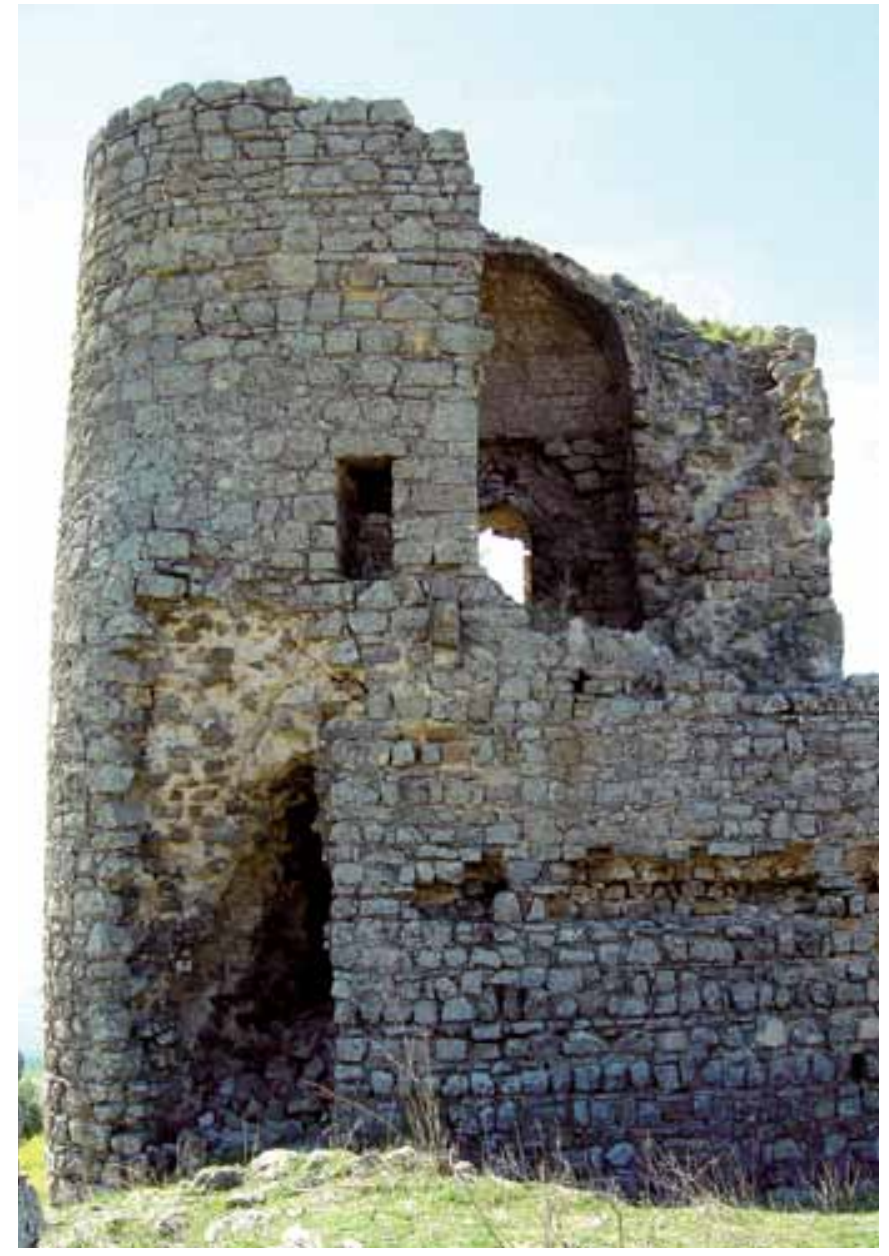

Detalle de la torre del homenaje del castillo de Castro el Viejo. Fuente: Archivo Museo Histórico de Baena

una escultura militar) constituyen una prueba evidente del culto imperial que los habitantes de esta ciudad rindieron a diversos miembros de la familia julio-claudia.

Tras el esplendor de la época romana altoimperial la ciudad fue perdiendo importancia de forma paulatina durante las épocas tardoantigua y visigoda. La presencia árabe está constatada, desde el califato hasta el s. XII, como evidencia el material cerámico y numismático y a través de algunas estructuras murarias. El castillo medieval que corona el punto más elevado del sitio es una obra ya cristiana, de fines del s. XIII o comienzos del s. XIV. Los documentos de la época lo citan con el nombre de Castro el Viejo y sabemos que perteneció al rey Alfonso X quien lo donó a Fernán Alfonso de Lastres en compensación por los servicios militares prestados durante la conquista, manteniendo así el papel estratégico que el lugar habia tenido durante siglos. Tras un corto periodo de tiempo en poder señorial pasó a manos del concejo de la ciudad de Córdoba, institución encargada de nombrar a sus alcaides. A comienzos del s. XVI quedó deshabitado definitivamente, siendo vendidas sus tierras (cortijo de Paredones de Medina y cortijo de las Virgenes) a particulares durante el s. XIX. Finalmente, a comienzos del s. XXI, el Ayuntamiento de Baena se ha hecho con toda la propiedad del yacimiento y viene desarrollando en él un amplio proyecto de recuperación y puesta en valor para convertirlo en un parque arqueológico. 